\title{
ELECTRON BEAM-PHYSICAL VAPOUR DEPOSITION OF ZIRCONIA CO-DOPED WITH YTTRIA AND NIOBIA
}

\author{
D. S. Almeida ${ }^{1}$, C. R. M. Silva ${ }^{1}$, M. C. A. $\mathrm{Nono}^{2}$, C. A. A. Cairo ${ }^{1}$ \\ ${ }^{1}$ Centro Técnico Aeroespacial, Instituto de Aeronáutica e Espaço, S. J. Campos, Brazil. \\ ${ }^{2}$ Instituto Nacional de Pesquisas Espaciais, Lab. Materiais e Sensores, S. J. Campos, Brazil. \\ dsa62@yahoo.com
}

\begin{abstract}
Turbine blades of airplanes and thermoelectric plants work in adverse conditions, with corrosive environment and high temperature and pressure. One way to improve the life or the working temperature of the blades is by the use of special coatings over metallic material applied by Electron Beam - Physical Vapour Deposition (EB-PVD). The most usual material for this application is zirconia doped with yttria. Addition of niobia, as a new configuration in this system, can reduce the thermal conductivity and improve mechanical properties of the coating. The purpose of this work is to show the technique for production of such coatings and the results of the addition of niobia taking in to consideration X-ray diffraction and scanning electron microscopy observations. First result shows a columnar structure with only tetragonal phase in the ceramic coating in the chemical composition range studied.
\end{abstract}

Keywords: EB-PVD, TBC, zirconia, niobia

\section{Introduction}

Turbine blades of airplanes and thermoelectric plants work in adverse conditions, with corrosive environment and high temperature and pressure. One way to improve the life or the work temperature of the blades is by the use of special coatings over metallic material applied by Electron Beam - Physical Vapour Deposition (EB-PVD). The most usual material for this application is zirconia doped with yttria ${ }^{1-9}$. Addition of niobia, as a new configuration in this 
system, can reduce the thermal conductivity and improve mechanical properties of the coating. The purpose of this work is to show the technique for production of such coatings and the results of the addition of niobia taking in to consideration X-ray diffraction and scanning electron microscopy observations.

\section{Literature Review}

It is well known that for $\mathrm{ZrO}_{2}$ to be utilised for technical applications the hightemperature polymorphs cubic (c) and tetragonal (t) phases, should be stabilised at ambient temperature by the formation of solid solutions which prevent deleterious tetragonal-tomonoclinic $(\mathrm{m})$ phase transformation. The alloying oxides, which lead to the stabilisation, are alkaline-earth, rare-earth, and actinide oxides. It has been suggested that the factors which may influence the stabilisation are size, valency, and concentration of solute cations and crystal structure of the solute oxides, where the valency and concentration determine the number of oxygen vacancies created by the formation of substitucional solid solutions ${ }^{10}$.

The addition of $\mathrm{Ta}_{2} \mathrm{O}_{5}, \mathrm{Nb}_{2} \mathrm{O}_{5}$, and $\mathrm{HfO}_{2}$ enhanced the transformability of $\mathrm{Y}_{2} \mathrm{O}_{3}-$ zirconias, which was indicated by an increase in phase transformation temperatures and fracture toughness. An alloying oxide which increases the c/a axial ratio (tetragonality) also increases the transformability ${ }^{11,12}$.

Because of their low thermal conductivity, zirconia-based ceramics are often used as thermal insulators over temperatures ranging from cryogenic to greater than $1200^{\circ} \mathrm{C}$, e. g., for thermal barrier coating (TBC). At temperatures greater than room temperature, the low thermal conductivity of the zirconias is based primarily from the scattering of phonons by point defects. The effectiveness of a point defect in reducing the thermal conductivity of a lattice depends on the difference in mass and ionic radius between the defect and the host atom, and also the change in atomic bonding's influence in the elastic constants ${ }^{13}$. 
When the dopants added to zirconia are subtetravalent oxides, e.g., yttria, calcia and magnesia, the most influential defects are the oxygen vacancies that are created for charge balance, while the cation substitutional defects in the zirconium lattice play a subsidiary role. When the dopants are tetravalent oxides, such as ceria, the substitucional cerium ions are the ones responsible for reducing the thermal conductivity of zirconia, although as much as 17 mol\% ceria is required to obtain the same conductivity reduction as $4 \mathrm{~mol} \% \mathrm{yttria}^{13,14}$.

When a trivalent oxide, e.g. $\mathrm{Y}_{2} \mathrm{O}_{3}$, is added to $\mathrm{ZrO}_{2}$ as stabiliser, certain amount of lattice defects, e.g. oxygen vacancies and negatively-charged solutes, are produced in the $\mathrm{ZrO}_{2}$ lattice. The thermal conductivity of partially stabilized- $\mathrm{ZrO}_{2}(\mathrm{PSZ})$ is determined by its defect structure and the defect associates between them. Pentavalent oxides are positively charged, opposite to the stabiliser, when dissolved in the $\mathrm{ZrO}_{2}$ lattice, the addition of these oxides in the PSZ will definitely affect the original defect structure, thus also its properties. $\mathrm{Ta}_{2} \mathrm{O}_{5}$ has been found to affect the phase stability and the electrical properties of $\mathrm{ZrO}_{2}$, and $\mathrm{Nb}_{2} \mathrm{O}_{5}$ has also been found to dramatically change the grain boundary electrical conductivity $^{15}$.

The effect of doping with pentavalent oxides such as tantala and niobia (cationic radii in the +5 oxidation state $\sim 0.68 \AA$ for both) indicate that both ions reside as substitucional defects in the zirconium lattice (ionic radius of the $\mathrm{Zr}^{4+}$ ion is $0.79 \AA$ ), annihilating oxygen vacancies generated by yttria doping. Thus, the defect chemistry generated by the two dopants is also identical and would be expected to scatter phonons due to the difference in ionic radius and atomic bonding ${ }^{13}$.

The phase diagram available for the $\mathrm{Nb}_{2} \mathrm{O}_{5}-\mathrm{ZrO}_{2}$ system ${ }^{16}$ at temperatures in excess of $1400^{\circ} \mathrm{C}$ indicate limited solubility of the pentavalent oxide in zirconia. However, co-doping with yttria has been observed to enhance their solubility in the tetragonal phase ${ }^{12,13}$. 
It is expected that the single-phase tetragonal niobia co-doped yttria zirconias will have low thermal conductivity than conventional $6-8 \%$ yttria stabilised zirconia, the material conventionally used for thermal barrier coating with others advantages, e. g., phase stability at high temperatures, cyclic life, ageing behaviour which may prove superior to those of conventional zirconia.

\section{Experimental}

The coated substrates were $50 \times 10 \times 0.2 \mathrm{~mm}$ plates of stainless steel SAE 304 . Both bond coat and ceramic top coat were EB-PVD deposited by the $30 \mathrm{~kW}$ electron beam furnace of CTA-IAE using current of $0.05-0.2 \mathrm{~A}$, voltage of $27 \mathrm{kV}$ and substrate temperature of $930^{\circ} \mathrm{C}$, the distance substrate/target was $150 \mathrm{~mm}$. The bond coating was a $15 \sim 30 \mu \mathrm{m}$ thick layer of Ni-31Cr-11Al-0.65Y alloy (wt. \%). The chemical compositions of ceramic coating, with a thickness of $20 \sim 30 \mu \mathrm{m}$, were changed and the nominal composition of the target is given in Table I.

The phase structure of the coating has been analysed by X-ray diffraction using a diffractometer Philips PW 1380/80 and on a diffractometer X'Pert - MRD Philips with a PW 3050 goniometer. The coatings composition was estimated by EDS analysis; their macrostructure and morphology was studied by a LEO 435 VPI scanning electron microscopy.

\section{Results and Discussion}

The results of EDS analysis performed on the ceramic coating are summarised on Table I. It is to be noted that the composition of the layers differs from the target, remarkable for the niobia concentration, probably due to the difference in melting point and vapour pressure between niobia, zirconia and yttria.

Figure 1 shows the X-ray diffractograms in scanning mode (left) and the high angular resolution (0.01 for $2 \theta$ ) spectra for (400) region (right) for all ceramic layers. The (400) 
region was selected because it is specific of the nonequilibrium tetragonal phase (i.e. forbidden by the cubic symmetry ${ }^{17}$ ). All samples show only tetragonal phase. The values of the cell parameters deduced from these diffraction patterns are reproduced in Table II.

Figure 2 shows the influence of the weight percentage of niobia and the tetragonality of zirconia based ceramic, as this percentage increase the ratio c/a (tetragonality) increases.

Figure 3 shows the typical microstructure of EB-PVD coatings, as seen by scanning electron microscopy on polished transverse section the ceramic layer and metallic bond coating, Figure 4 shows a fractured cross section where is evident de columnar structure.

\section{Conclusions}

This new ceramic system allows attaining coatings with microstructure similar of the conventional TBCs. As in conventional TBCs, only the nonequilibrium tetragonal phase was found in the ceramic coating for the chemical composition range studied and the tetragonality of the unit cell increases with the amount of niobia in the ceramic layer coating.

\section{Acknowledgments}

The authors like to thank FAPESP for the financial support.

\section{References}

1- Xu, H., Goug, S., Deng, L. Preparation of thermal barrier coating for gas turbine blades by EB-PVD, Beijing, China, Thin Solid Films, 334, 1998.

2- Schulz, U. et ali, Two-source jumping beam evaporation for advanced EB-PVD TBC systems, Cologne, Germany, Surface and Coating Technology, p. 40-48, 2000.

3- Evans, A. G. et ali, Mechanics-based Scaling Laws for the Durability of TBC, Progress in Materials Science, 46, 249-271, 2001.

4- Zhu, D. et ali, Thermal conductivity of EB-PVD thermal barrier coatings evaluated by a steady -state laser heat flux technique, NASA/TM-2000-210238. 
5- Goward, G. W., Progress in coating for gas turbine airfoils, Clinton, USA, Surface and Coating Technology, 108-109, 1998.

6- Nicholls, J.R., Deakin, M.J., Rickerby, D. S., A comparison between the erosion behavior of thermal spray and electron beam physical vapor deposition thermal barrier coating, Wear, p 233-235, 1999.

7- Czek, N. et ali, Studies of the bond-coat oxidation and phase structure of TBCs, Surface and Coating Technology, 113, 1999.

8- Hass, D.D., Thermal Barrie Coatings via Directed Vapor Deposition, Doctor Degree Thesis, University of Virginia, May, 2001.

9- Almeida, D. S. et ali, Manufatura de Revestimentos como Forma de Barreira Térmica, Anais do Congresso Brasileiro de Engenharia e Ciência dos Materiais, Natal, 2002.

10- Kim, D. J., Effect of $\mathrm{Ta}_{2} \mathrm{O}_{5}, \mathrm{Nb}_{2} \mathrm{O}_{5}$, and $\mathrm{HfO}_{2}$ alloying on the transformability of $\mathrm{Y}_{2} \mathrm{O}_{3}$ stabilized tetragonal $\mathrm{ZrO}_{2}$, Journal of American Ceramic Society, 73[1]115-20, 1990.

11-Kim, D. J. e Tien, T. Y., Phase stability and physical properties of cubic and tetragonal $\mathrm{ZrO}_{2}$ in the system $\mathrm{ZrO}_{2}-\mathrm{Y}_{2} \mathrm{O}_{3}-\mathrm{Ta}_{2} \mathrm{O}_{5}$, Journal of American Ceramic Society, $74[12] 3061-65,1991$.

12- Lee, D. Y., et ali, Low thermal phase stability and mechanical properties of $\mathrm{Y}_{2} \mathrm{O}_{3}$ and $\mathrm{Nb}_{2} \mathrm{O}_{5}$ co-doped tetragonal zirconia polycrystal ceramics, Journal of Materials Science Letters, 17, pp. 185-187, 1998.

13-Raghavan, S. et ali, Thermal properties of zirconia co-doped with trivalent and pentavalent oxides, Acta Materialia, 49 (2001) 169-179.

14- Li, P. and Chen, I-W., Effect of dopants on zirconia stabilization - An X-ray absortion study: II, tetravalent dopants, J. Am. Ceram. Soc., 77[5] 1281-88, 1994.

15-Guo, X. and Wang, Z., Effect of niobia on the defect structure of yttria-stabilized zirconia, Journal of the European Ceramic Society, 18, pp. 237-240, 1998. 
16- Roth, R. S. and Coughanour, L. W., in Phase Diagrams for Ceramists. Vol.1, ed. E. M. Levin, C. R. Robbins, H. F. Macmurdie and M. K. Reser. The American Ceramic Socity, Columbus, OH, 1964, p. 144.

17- Lelait, L, Alpérine, S., Diot, C., Microstructural investigations of EB-PVD thermal barrier coatings, Journal de Physique III, vol. 3, pp. 645-654, 1993.

\section{Tables}

TABLE I: Chemical composition of the Target and EB-PVD ceramic Coating

\begin{tabular}{|c|c|c|c|c|c|c|}
\hline Sample & \multicolumn{2}{|c|}{ wt. \% zirconia } & \multicolumn{2}{|c|}{ wt. \% yttria } & \multicolumn{2}{|c|}{ wt. \% niobia } \\
\hline & Target & Coating & Target & Coating & Target & Coating \\
\hline A1 & 92.0 & 92.7 & 8.0 & 7.3 & - & - \\
\hline $\mathbf{A 2}$ & 80.0 & 81.0 & 9.2 & 9.8 & 10.8 & 9.2 \\
\hline $\mathbf{A 3}$ & 74.8 & 71.2 & 10.2 & 9.3 & 15.0 & 19.5 \\
\hline $\mathbf{A 4}$ & 72.2 & 70.6 & 8.3 & 5.0 & 19.5 & 24.4 \\
\hline
\end{tabular}

Table II: Lattice parameters of tetragonal phase of the coatings

\begin{tabular}{|c|c|c|c|c|c|c|}
\hline \multirow[b]{2}{*}{ Sample } & \multirow[b]{2}{*}{111} & \multirow[b]{2}{*}{400} & \multicolumn{3}{|c|}{ cell parameters } & \multirow{2}{*}{$\begin{array}{c}\rho_{\text {theor }}{ }^{*} \\
\left(\mathrm{~g} / \mathrm{cm}^{3}\right)\end{array}$} \\
\hline & & & $\mathbf{a}(\AA)$ & c $(\AA)$ & $\mathbf{a} / \mathbf{c}$ & \\
\hline A1 & $30.19^{\circ}$ & $74.27^{\circ}$ & 5.104 & 5.162 & 1.012 & 6.048 \\
\hline A2 & $30.25^{\circ}$ & $74.45^{\circ}$ & 5.093 & 5.154 & 1.012 & 6.110 \\
\hline A3 & $30.23^{\circ}$ & $74.45^{\circ}$ & 5.093 & 5.164 & 1.014 & 6.148 \\
\hline A4 & $29.89^{\circ}$ & $74.51^{\circ}$ & 5.090 & 5.354 & 1.052 & 5.980 \\
\hline
\end{tabular}


Figures
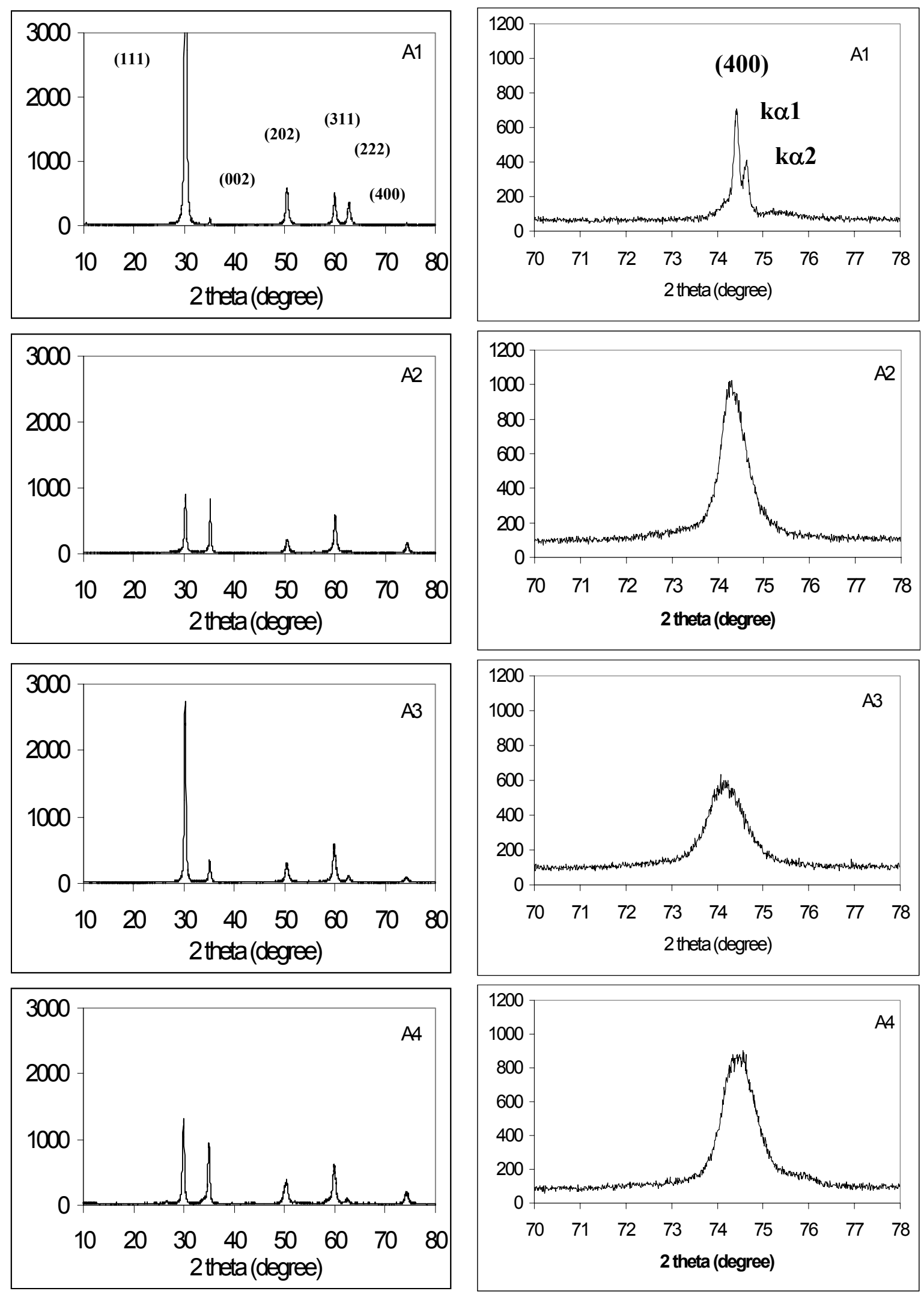

Fig.1: X-ray diffractograms in scanning mode (left) and the high resolution spectra for (400) region (right) for all $\mathrm{A} 1, \mathrm{~A} 2, \mathrm{~A} 3$, and $\mathrm{A} 4$ ceramic coatings. 


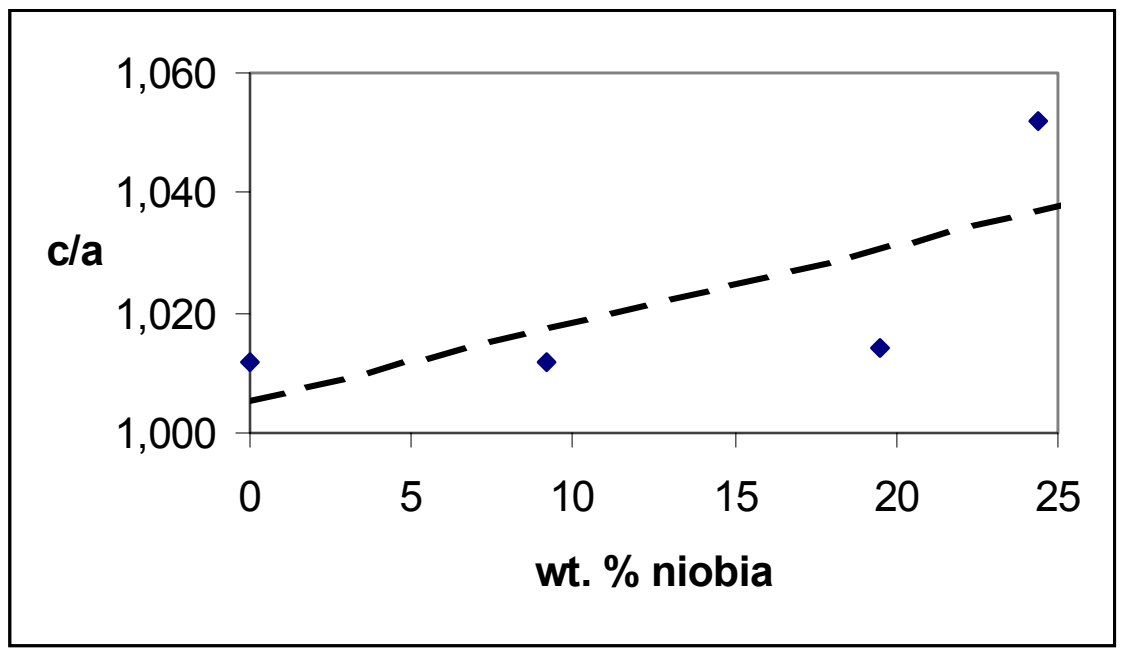

Fig. 2: Relation between weight percentage of niobia and tetragonality.

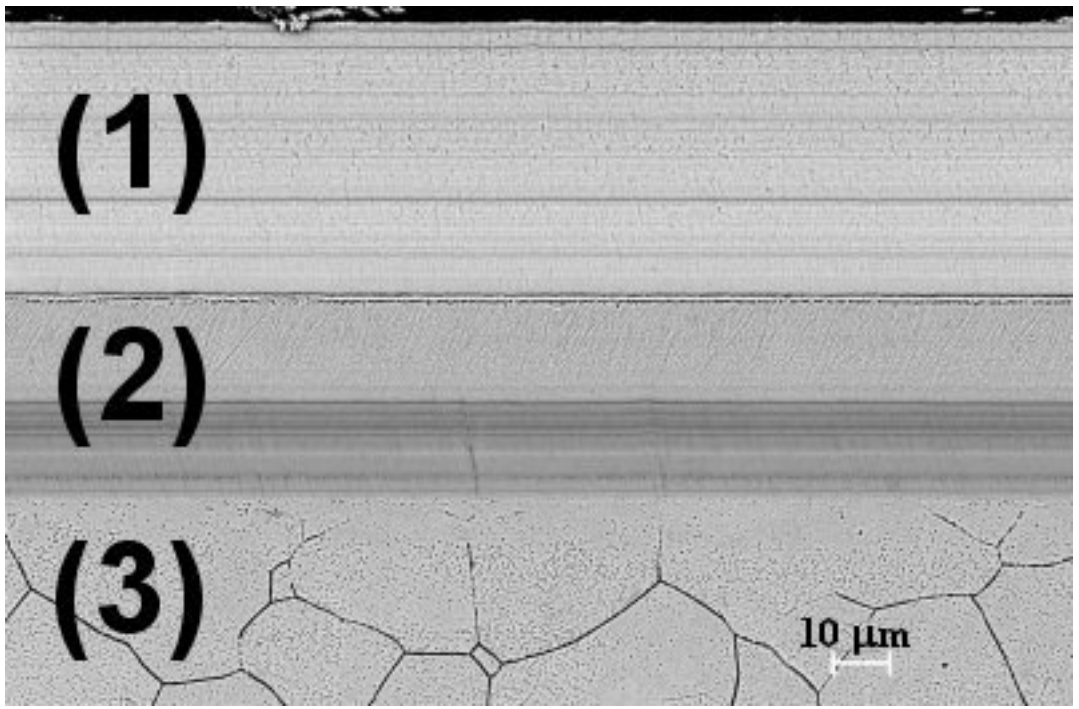

Fig. 3: EB-PVD thermal barrier coating; polished cross section; scanning electron microscopy. (1) Ceramic layer; (2) Metallic bond layer; (3) Stainless steel substrate.

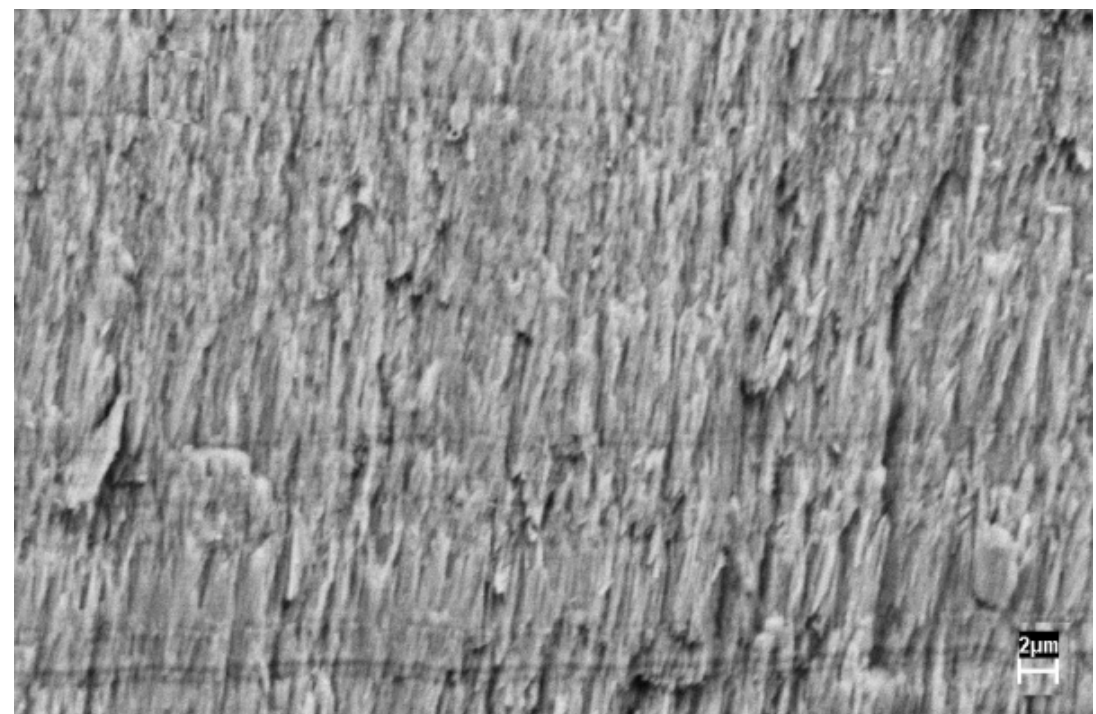

Fig. 4: EB-PVD thermal barrier coating; fractured cross section of the ceramic layer; scanning electron microscopy. 